\title{
Traffic Noise Assessment at Residential Areas in Skudai, Johor
}

\author{
F.S. Sulaiman ${ }^{1}, N$. Darus ${ }^{1}, N$. Mashros ${ }^{2, *}, Z$. Haron $^{1}$, and $K$. Yahya ${ }^{1}$ \\ ${ }^{1}$ Department of Structure and Materials, Faculty of Civil Engineering, Universiti Teknologi Malaysia, \\ 81310 Johor Bahru, Johor, Malaysia \\ ${ }^{2}$ Department of Geotechnics and Transportation, Faculty of Civil Engineering, Universiti Teknologi \\ Malaysia, 81310 Johor Bahru, Johor, Malaysia
}

\begin{abstract}
Vehicles passing by on roadways in residential areas may produce unpleasant traffic noise that affects the residents. This paper presents the traffic noise assessment of three selected residential areas located in Skudai, Johor. The objectives of this study are to evaluate traffic characteristics at selected residential areas, determine related noise indices, and assess impact of traffic noise. Traffic characteristics such as daily traffic volume and vehicle speed were evaluated using automatic traffic counter (ATC). Meanwhile, noise indices like equivalent continuous sound pressure level $\left(\mathrm{L}_{\text {Aeq }}\right)$, noise level exceeded $10 \%\left(\mathrm{~L}_{10}\right)$ and $90 \%\left(\mathrm{~L}_{90}\right)$ of measurement time were determined using sound level meter (SLM). Besides that, traffic noise index $\left(\mathrm{T}_{\mathrm{NI}}\right)$ and noise pollution level $\left(\mathrm{L}_{\mathrm{NP}}\right)$ were calculated based on the measured noise indices. The results showed an increase in noise level of 60 to $70 \mathrm{dBA}$ maximum due to increase in traffic volume. There was also a significant change in noise level of more than 70 dBA even though average vehicle speed did not vary significantly. Nevertheless, $\mathrm{L}_{\mathrm{Aeq}}, \mathrm{T}_{\mathrm{NI}}$, and $\mathrm{L}_{\mathrm{NP}}$ values for all sites during daytime were lower than the maximum recommended levels. Thus, residents in the three studied areas were not affected in terms of quality of life and health.
\end{abstract}

\section{Introduction}

Noise can cause stress, disturb sleep, disrupt activities, hinder work, and impede learning [1]. Therefore, noise pollution has always been a significant environmental problem for humans. It can be defined as unwanted sound that intrudes humans' daily activities. Sound pressure is a basic measurement of air vibration. Furthermore, the range of sound pressure that can be detected by human ears is very wide whereby these levels are measured in logarithmic scale in the unit of decibel (dB) [2]. Traffic is a dominant noise source in urban and rural environments. Noise sources include those from motor vehicles, aircrafts, and rail transport. This noise originates from the engine and frictional contact between the vehicle and the ground, and is affected by traffic flow rate that depends on vehicle's speed and road's surface condition [3].

\footnotetext{
* Corresponding author: $\underline{\text { mnordiana@utm.my }}$
} 
Nowadays, the living environment in many residential areas has been deteriorating due to the increase in traffic volume, which resulted in causing noise pollution that affected residents [4]. Environmental awareness and knowledge in impact of noise on health, performance, and well-being, are becoming increasingly important to curb noise pollution. The World Health Organization (WHO) has described noise as the principle environmental nuisance in industrial nations. Besides that, WHO also recognised it as a harmful pollution that causes adverse psychosocial and physiologic effects on human health. For example, a noise pollution study was conducted in Fulton County, Georgia. The research highlighted that many residents were exposed to high noise levels that put them at risk of annoyance or sleep disturbance, which can lead to serious health consequences [5].

Hence, determining traffic noise level in residential areas will help in understanding the actual condition regarding noise pollution in that environment. Then, the results will indicate whether precautions or certain actions are sufficient to handle the traffic noise issue among the affected neighbourhoods. Since traffic noise from roadways, especially those with higher traffic volume and vehicle speed, creates problems to nearby residents, this study intends to evaluate traffic noise at selected residential areas in Skudai, Johor, Malaysia. This study was conducted according to the objectives, namely, evaluating traffic characteristics at selected residential areas, determining related noise indices, and assessing impact of traffic noise on nearby residents.

\section{Methodology}

This study was conducted in three main stages: (1) evaluation of traffic characteristics; (2) determination of noise indices; and (3) assessment of traffic noise impact. The details of each stage are described in the following sections.

\subsection{Evaluation of traffic characteristics}

Three residential areas, Site 1-Taman Universiti, Site 2-Taman Sri Skudai, and Site 3Bandar Baru Kangkar Pulai, located around Skudai, Johor were selected as sampling locations. These neighbourhoods were selected based on its high daily traffic volume, flat and straight roadways, single carriageways, and location of at least $70 \mathrm{~m}$ away from the nearest traffic light with the assumption that most vehicles in the traffic stream had already reached a steady speed [6]. To acquire the traffic characteristics of each sampling location, automatic traffic counter (ATC) was used in this study. Fig. 1 illustrates ATC's pneumatic road tubes configuration utilised on a single carriageway whereby two tubes are placed parallel to each other with $1 \mathrm{~m}$ spacing. The data recorder connected to the pneumatic road tubes was secured in a safety box, positioned at the roadside to avoid any loss or damage.

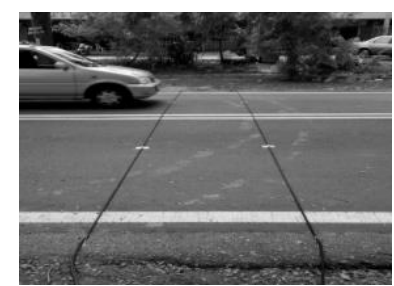

(a) Pneumatic tubes

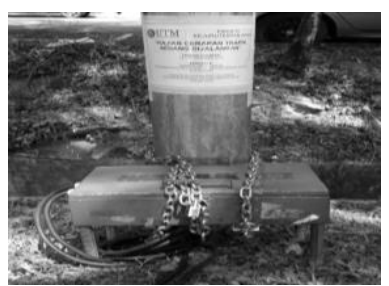

(b) Safety box

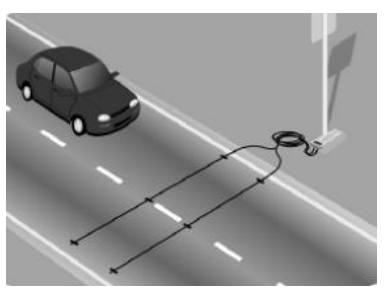

(c) Installation layout

Fig. 1. Installation of ATC.

The traffic characteristics study was conducted for three days (Monday, Tuesday, and Wednesday) within a week. The start and end days of the week were excluded to avoid 
different traffic behaviours at sampling locations. The ATC was installed continuously for 24 hours to observe traffic characteristics at sampling locations. Furthermore, the peak period of measurement was determined because morning ( 7 a.m. to 8 a.m.), afternoon (12 p.m. to 1 p.m.), and evening (6 p.m. to 7 p.m.) peak hours contributed to high noise level. The parameters considered for this traffic study were traffic volume and vehicle speed. Data output that included traffic volume, vehicle speed, and composition were presented in the data recorder, Metro Count Software.

\subsection{Determination of noise indices}

The second stage in this study was conducted using a Pulsar Type 1 sound level meter (SLM) to measure related noise indices such as equivalent continuous sound pressure level $\left(\mathrm{L}_{\text {Aeq }}\right)$, and noise level exceeded $10 \%\left(\mathrm{~L}_{10}\right)$ and $90 \%\left(\mathrm{~L}_{90}\right)$ of measurement time. Fig. 2 shows the installation of SLM at sampling locations. The microphone must be positioned at a height of $1.5 \mathrm{~m}$ above the ground level, which corresponds to the ear level of an individual with average height [7]. It was calibrated prior and after the measurement to ensure a reading error within the permissible value of $\pm 0.5 \mathrm{dBA}$. On the other hand, SLM was placed $7.5 \mathrm{~m}$ away from the middle of the nearest travel lane [8]. Noise measurement was conducted according to ISO 1996 guidelines [9-11]. It was carried out during daylight starting from 7 a.m. to 7 p.m. for three days under a good weather condition.

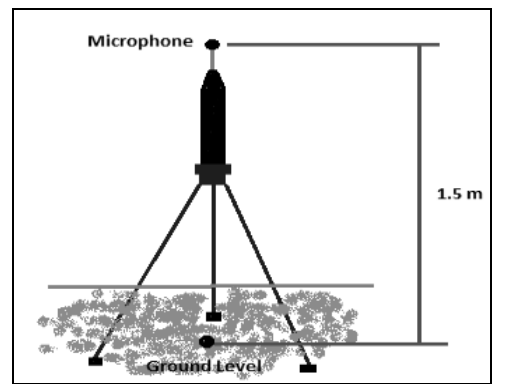

(a) Height of SLM

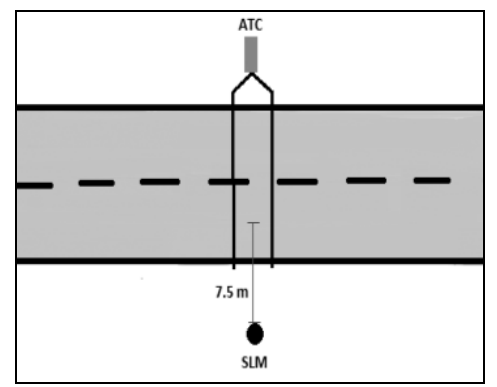

(b) Distance of SLM

Fig. 2. Installation of SLM.

\subsection{Assessment of traffic noise impact}

Traffic noise index $\left(\mathrm{T}_{\mathrm{NI}}\right)$ and noise pollution level $\left(\mathrm{L}_{\mathrm{NP}}\right)$ were calculated based on the measured noise indices i.e. $\mathrm{L}_{\text {Aeq }}, \mathrm{L}_{10}$, and $\mathrm{L}_{90}$. $\mathrm{T}_{\mathrm{NI}}$ was derived by combining $\mathrm{L}_{10}$ and $\mathrm{L}_{90}$ values. In addition, $T_{N I}$ attempts to make allowance for noise variability with respect to $L_{10}$ level [12]. Moreover, $\mathrm{T}_{\mathrm{NI}}$ values should not exceed $74 \mathrm{dBA}$ to avoid dissatisfaction among nearby residents. Meanwhile, $\mathrm{L}_{\mathrm{NP}}$ considers the variations in sound signal that serves as a better indicator of environment pollution [13]. $\mathrm{T}_{\mathrm{NI}}$ and $\mathrm{L}_{\mathrm{NP}}$ were computed using Equations 1 and 2, respectively [14]. Besides that, $L_{\text {Aeq }}$ and $L_{N P}$ values were compared with the standard guidelines from WHO and Department of Environment (DOE), Malaysia [15, 16]. Both guidelines stated that the tolerance limit due to traffic noise in urban areas should not exceed 55 dBA during daytime.

$$
\begin{gathered}
T_{\mathrm{NI}}=4\left(L_{10}-L_{90}\right)+L_{90}-30 \\
L_{\mathrm{NP}}=L_{\mathrm{eq}}+\left(L_{10}-L_{90}\right)
\end{gathered}
$$




\section{Results and Discussions}

\subsection{Traffic volume}

Table 1 displays the daily traffic volume for three days measured at selected road sections from three sampling sites. Based on the data, Site 3 recorded the highest total traffic volume with 60,153 vehicles. This indicates that Site 3 is the busiest road compared to other sites. Meanwhile, the total traffic volume at Sites 1 and 2 were not much different with 21,418 and 20,268 vehicles, respectively. Additionally, the daily traffic volume for Monday, Tuesday, and Wednesday recorded a similar value, for all sites.

Table 1. Daily traffic volume.

\begin{tabular}{|c|c|c|c|}
\hline Day & Site 1 & Site 2 & Site 3 \\
\hline Monday & 6,543 & 7,246 & 20,092 \\
\hline Tuesday & 6,794 & 7,252 & 19,897 \\
\hline Wednesday & 6,931 & 6,920 & 20,164 \\
\hline Total & 20,268 & 21,418 & 60,153 \\
\hline
\end{tabular}

Fig. 3 depicts the distribution of traffic volume within 24 hours for three days. It clearly shows that the highest traffic volume for each location occurred during morning ( 7 a.m. to 8 a.m.) and evening ( 6 p.m. to 7 p.m.) peak hours. These peak hours are typical rush hours at all sampling locations. This is due to the large number of private and public vehicles transporting passengers or goods through main traffic routes. On the other hand, the afternoon (12 p.m. to 1 p.m.) peak hour recorded a slightly lower volume in comparison to morning and evening peak hours.

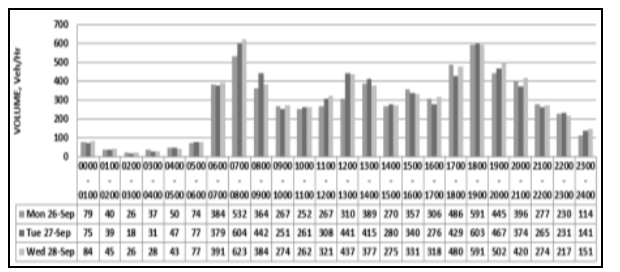

(a) Site 1

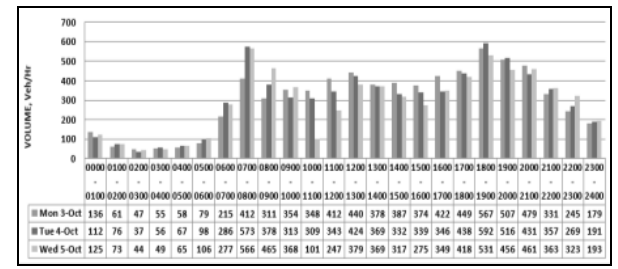

(b) Site 2

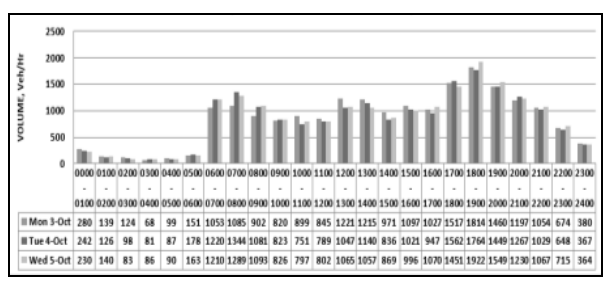

(c) Site 3

Fig. 3. Traffic volume at three sampling locations.

\subsection{Traffic speed}

Traffic speed distributions are presented in histograms with a class interval of $10 \mathrm{~km} / \mathrm{h}$. Fig. 4 displays the spot speed distributions of 300 vehicles during morning, afternoon, and evening peak hours at all sampling locations. Majority of spot speed at Sites 1 and 3 were within 41 to $50 \mathrm{~km} / \mathrm{h}$ during all peak periods. Meanwhile, most vehicles' speed at Site 2 during the three peak periods was between 31 and $40 \mathrm{~km} / \mathrm{h}$. 
During the evening peak hour at Site 3, vehicle speed was slightly higher and reached $80 \mathrm{~km} / \mathrm{h}$. This might be due to the different lane width at Site 3 compared to Sites 1 and 2. Besides that, all vehicular speed data collected during peak hours for three days were then converted into cumulative frequency distribution. The $85^{\text {th }}$ percentile speed was determined to observe the majority speed selected by the motorists to reach their destination.

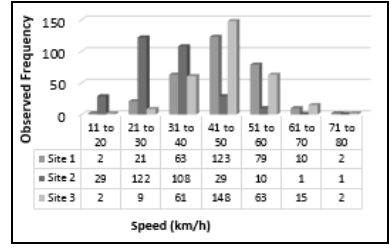

(a) Site 1

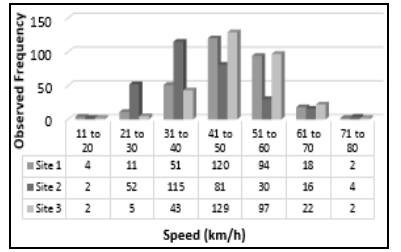

(b) Site 2

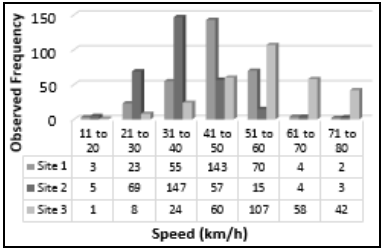

(c) Site 3

Fig. 4. Histogram of spot speed data for all peak hours.

Based on Fig. 5 to 7, the 85 th percentile speed at Site $2(35.14 \mathrm{~km} / \mathrm{h})$ was lower than Sites 1 and $3(45.50 \mathrm{~km} / \mathrm{h}$ and $41.45 \mathrm{~km} / \mathrm{h}$, respectively). Moreover, all sites recorded a slight difference, except for evening peak hour at Site 3, whereby the 85th percentile speed was $64.98 \mathrm{~km} / \mathrm{h}$. This value is higher in comparison to the other sites and could be due to higher traffic volume and wider lane width at Site 3, which allowed drivers to speed up their vehicles. Nonetheless, the traffic speed analysis showed that vehicles at all sites did not exceed the speed limits of $60 \mathrm{~km} / \mathrm{h}$ for Sites 1 and 2 and $80 \mathrm{~km} / \mathrm{h}$ for Site 3 . Thus, it can be summarised that speed was higher during morning and evening peak hours, whereby most drivers were rushing to reach their workplace or other destinations.
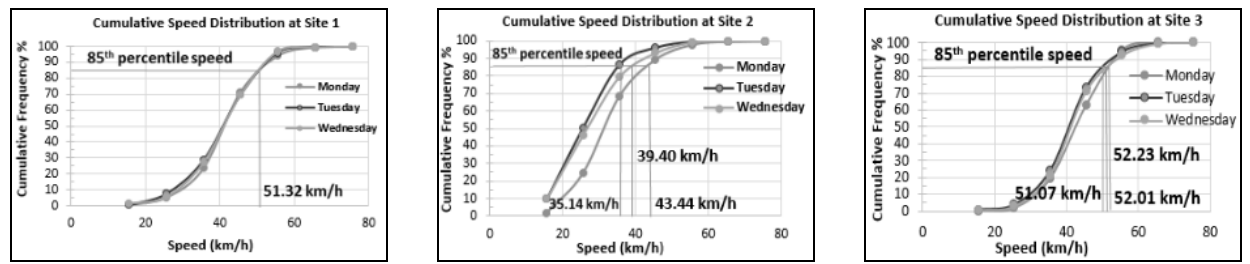

Fig. 5. Cumulative distribution of spot speed data during morning peak hour.
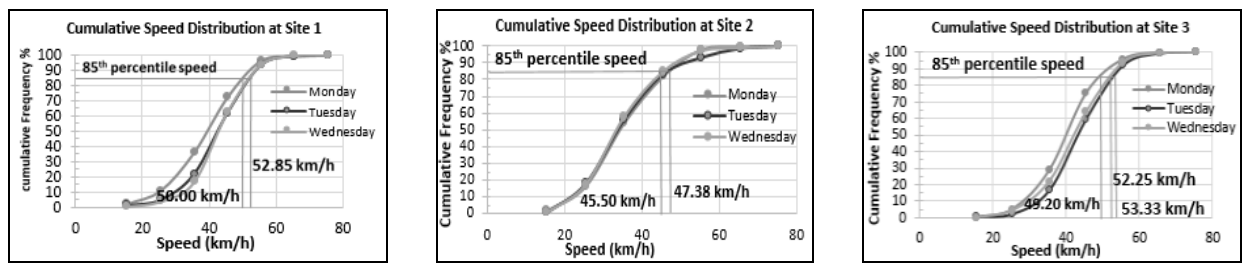

Fig. 6. Cumulative distribution of spot speed data during afternoon peak hour.
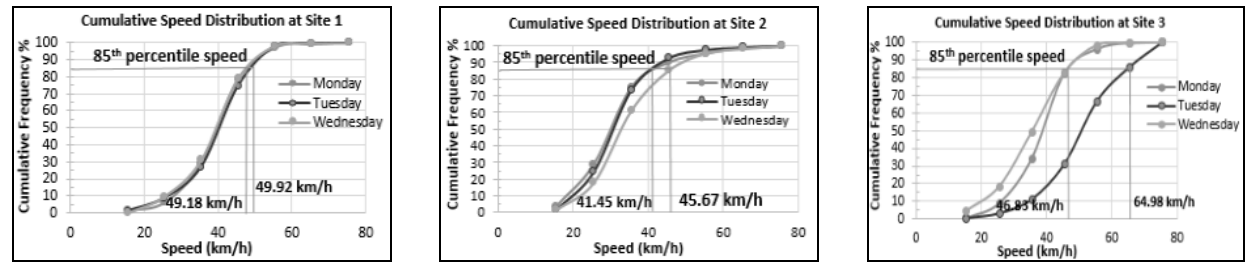

Fig. 7. Cumulative distribution of spot speed data during evening peak hour. 


\subsection{Noise level}

According to on-site noise measurement, background noise level at Sites 1 and 2 was 45 dBA whereas at Site 3 it was 48 dBA. Fig. 8 illustrates $\mathrm{L}_{\text {Aeq }}$ over a 12 hours period at three sampling locations in which many peak noise levels can be seen. Furthermore, most peak noise levels, which were between 60 and $75 \mathrm{dBA}$, occurred during morning and evening peak hours. Besides that, noise variation from 11 a.m. until 4 p.m. showed several peak noise levels. This scenario indicates that increase in noise level can be associated with certain driver behaviours such as honking, speeding up, and causing other sources of noise.
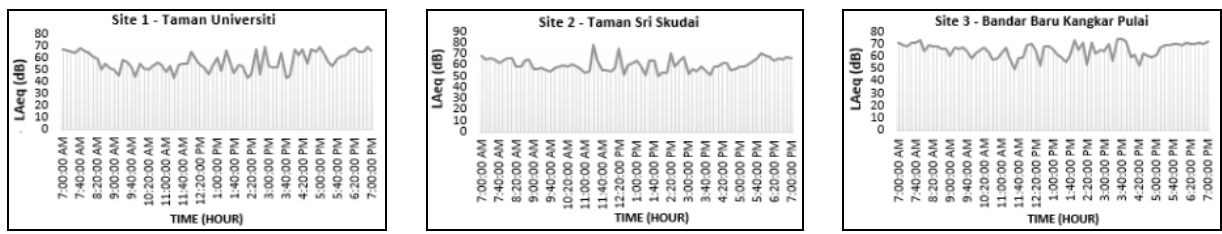

Fig. 8. $\mathrm{L}_{\text {Aeq }}$ over a 12 hours period at sampling locations.

\subsection{Relationship between traffic volume and noise level}

Fig. 9 illustrates the range of noise level, with Sites 1 and 2 scoring within 50-70 dBA while Site 3 recorded a higher noise level of 60-70 dBA. In general, the noise level produced was slightly higher during morning and evening peak hours. In addition, it was observed that noise level decreased about 5-10 dBA after morning peak hour between 9 a.m. to 4 p.m. Then, it continuously increased after 4 p.m. until the evening peak hour. Based on these results, noise level decreased as traffic volume decreased and vice versa. These results are in agreement with previous studies whereby loudness of traffic noise generally increased due to heavier traffic volumes. A total of 200 vehicles passing in one hour sound half as loud as 2000 vehicles. Based on previous study, traffic volume is a nonvehicle noise source and one of the major sources of traffic noise [17].

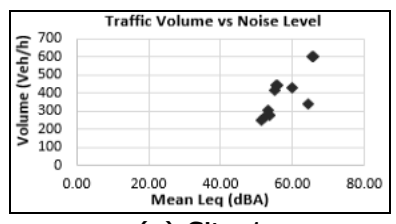

(a) Site 1

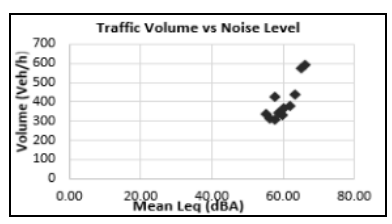

(b) Site 2

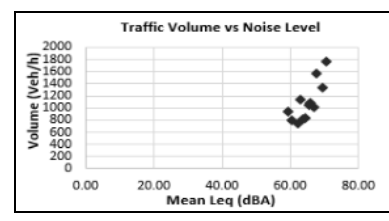

(c) Site 3

Fig. 9. Traffic volume vs. noise level.

\subsection{Relationship between traffic speed and noise level}

Fig. 10 shows that noise level increased as speed increased and vice versa. Furthermore, noise level for each sampling location increased during morning and evening peak hours. Noise due to engine transmission becomes a predominant influence at a lower speed. On the other hand, at a higher speed, the main influence would be interaction between vehicle tire and road surface. Moreover, noise level typically increases when a vehicle is accelerating. In this study, maximum vehicle speed for all sites was recorded during the evening peak hours, which were 52.3, 56.1, and $61.5 \mathrm{~km} / \mathrm{h}$ for Sites 1, 2, and 3, respectively. In addition, highest noise level was observed at Site 3 . Hence, this proves that traffic speed plays significant role in increasing traffic noise level. Reducing traffic noise is the most immediate way to reduce traffic noise level by enforcing suitable speed limit. 


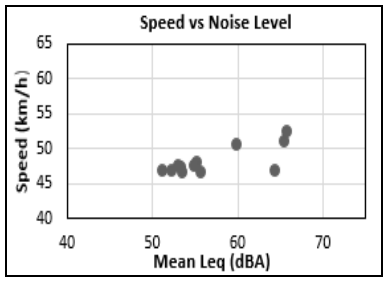

(a) Site 1

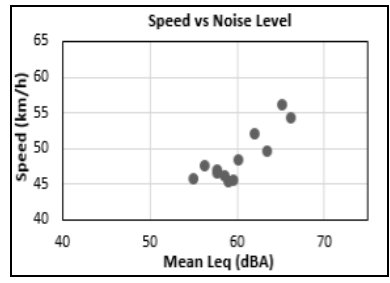

(b) Site 2

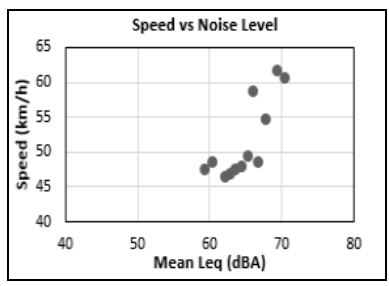

(c) Site 3

Fig. 10. Traffic speed vs. noise level.

\subsection{Traffic noise impact}

Table 2 presents the related noise indices and its comparison with DOE and WHO guidelines. $\mathrm{L}_{\mathrm{Aeq}}, \mathrm{L}_{\mathrm{NP}}$, and $\mathrm{T}_{\mathrm{NI}}$ values at all sites recorded similar values while the highest values were found at Site 3. The $\mathrm{L}_{\mathrm{Aeq}}$ and $\mathrm{L}_{\mathrm{NP}}$ values were compared with DOE and WHO limits. Meanwhile, $\mathrm{T}_{\mathrm{NI}}$ values were compared with the limit of $74 \mathrm{dBA}$. Based on the results obtained, $\mathrm{L}_{\mathrm{Aeq}}$ and $\mathrm{L}_{\mathrm{NP}}$ values for all sites were within the limit of $55 \mathrm{dBA}$ as specified by DOE and WHO. For $\mathrm{T}_{\mathrm{NI}}$, all values were lower than $74 \mathrm{dBA}$, which is the limit for residential area. Therefore, traffic noise impact is not a concern at all sites since measured values were within permissible limits.

Table 2. Noise indices and comparison with guidelines

\begin{tabular}{|c|c|c|c|c|c|c|}
\hline \multirow[t]{2}{*}{ Time } & \multirow[t]{2}{*}{ Site } & \multirow[t]{2}{*}{$\mathrm{L}_{10}, \mathrm{dBA}$} & \multirow[t]{2}{*}{ L90, dBA } & $\mathrm{L}_{\mathrm{Aeq}}, \mathrm{dBA}$ & $\mathrm{L}_{\mathrm{NP}}, \mathrm{dBA}$ & \multirow{2}{*}{$\frac{\mathrm{T}_{\mathrm{NI}}, \mathrm{dBA}}{74 \mathrm{dBA}}$} \\
\hline & & & & \multicolumn{2}{|c|}{$55 \mathrm{dBA}$} & \\
\hline \multirow{3}{*}{$\begin{array}{c}7 \text { a.m. }-8 \\
\text { a.m. } \\
\text { (1 hour) }\end{array}$} & 1 & 66.9 & 56.4 & 65.8 & 76.3 & 68.4 \\
\hline & 2 & 68.2 & 54.6 & 65.2 & 78.8 & 79.0 \\
\hline & 3 & 72.5 & 54.4 & 69.4 & 87.5 & 96.8 \\
\hline \multirow{3}{*}{$\begin{array}{c}8 \text { a.m. }-6 \\
\text { p.m. } \\
(10 \text { hours) }\end{array}$} & 1 & 62.3 & 54.1 & 54.4 & 62.6 & 56.9 \\
\hline & 2 & 61.5 & 52.3 & 57.3 & 66.5 & 59.1 \\
\hline & 3 & 64.1 & 53.7 & 58.2 & 68.6 & 65.3 \\
\hline \multirow{3}{*}{$\begin{array}{c}6 \text { p.m. }-7 \\
\text { p.m. } \\
\text { (1 hour) }\end{array}$} & 1 & 70.4 & 55.4 & 65.8 & 80.8 & 85.4 \\
\hline & 2 & 65.9 & 55.0 & 66.2 & 77.1 & 68.6 \\
\hline & 3 & 71.6 & 59.4 & 70.4 & 82.6 & 78.2 \\
\hline \multirow{3}{*}{$\begin{array}{l}15 \text { hours } \\
\text { (DOE) }\end{array}$} & 1 & 50.7 & 43.5 & 45.0 & 52.2 & 42.2 \\
\hline & 2 & 49.9 & 42.2 & 47.0 & 54.7 & 43.2 \\
\hline & 3 & 52.3 & 43.4 & 48.1 & 57.1 & 49.2 \\
\hline \multirow{3}{*}{$\begin{array}{l}16 \text { hours } \\
\text { (WHO) }\end{array}$} & 1 & 47.5 & 40.8 & 42.2 & 48.9 & 37.7 \\
\hline & 2 & 46.8 & 39.5 & 44.0 & 51.3 & 38.7 \\
\hline & 3 & 49.1 & 40.7 & 45.1 & 53.5 & 44.3 \\
\hline
\end{tabular}

\section{Conclusions}

This study has assessed traffic noise at three selected residential areas. Traffic characteristics and noise indices data were collected and then analysed according to the study's objectives. It was determined that traffic volume and vehicle speed are the main factors that influence increase of noise level. Site 3 recorded the highest traffic volume compared to Sites 1 and 2. Furthermore, traffic speed at all sites was in the range of 31 to $50 \mathrm{~km} / \mathrm{h}$. Other than that, noise level of 60 to $75 \mathrm{dBA}$ was recorded during peak hours. Nonetheless, $\mathrm{L}_{\text {Aeq }}, \mathrm{L}_{\mathrm{NP}}$, and $\mathrm{T}_{\mathrm{NI}}$ values were lower than the maximum recommended noise limits. Thus, nearby residents' daily activities and health conditions are not affected. 
The authors would like to express their deep gratitude to the Ministry of Higher Education, Malaysia and Universiti Teknologi Malaysia for providing financial assistance (Ref: FRGS/1/2016/TK08/UTM/02/2, Cost Centre No.: R.J130000.7822.4F867) and opportunity to carry out this research.

\section{References}

1. B. Thagesen, Tech. Uni. of Denmark, F \& FN Spon, (1996)

2. D. Pal, D. Bhattacharya, Adv. in Fuzzy Sys 8 (2012)

3. M. J. Damavandi, M. Nowrouzi, Energy and Env. 266 (2012)

4. A. A. Kadar Hamsa, M. Miura, S. Inokuma, Y. Nishimura, J. of Asian Arch. and Build. Eng. 5 (2006)

5. K. Ki Hyun, J. Shamin Ara, K. Ehsanul, J. C. B. Richard, Env. Int 60 (2013)

6. G. Belojević, B. Jakovljević, O. Aleksić, Env. Int 23 (1997)

7. D. Ouis, J. Env. Psy 21 (2001)

8. H. K. Sy, P. P. Ong, S. H. Tang, K. L. Tan. App. Acoustics 18 (1985)

9. International Organization for Standardization, ISO 1996-1, Switzerland (1982)

10. International Organization Standardization, ISO 1996-2, Switzerland (1987)

11. International Organization Standardization, ISO 1996-3,Switzerland (1987)

12. P. D. Marathe, IJED 9 (2012)

13. B. K. Swain, S. Goawami, Int. J. E. Env 4 (2013)

14. L. Bengang, S. Tao, R. W. Dawson, App. Acoustics 63 (2002)

15. Department of Environment, Ministry of Natural Resources and Environment, Malaysia (2004)

16. World Health Organization, Congress on environmental health, OSLO (2000)

17. M. J. Crocker (Ed.) Noise and Vibration Control. (New Jersey, John Wiley \& Sons, 2007) 